MATEC Web of Conferences 11,01001 (2014)

DOI: $10.1051 /$ matecconf $/ 20141101001$

(C) Owned by the authors, published by EDP Sciences, 2014

\title{
Specific Examples of Hybrid Alkaline Cement
}

\author{
Ana Fernández-Jiménez, Inés García-Lodeiro, Shane Donatello, Olga Maltseva and Ángel Palomo \\ Department of cement and materials recycling, \\ Eduardo Torroja Institute of construction sciences, (IETcc-CSIC), Madrid, Spain,
}

Abstract.

\begin{abstract}
Hybrid alkaline cements are obtained by alkali-activating cementitious blends in the $\mathrm{Na}_{2} \mathrm{O}-\mathrm{CaO}-\mathrm{SiO}_{2}-\mathrm{Al}_{2} \mathrm{O}_{3}-\mathrm{H}_{2} \mathrm{O}$ system. The present paper discusses the results of activating different cementitious blends containing a low OPC clinker content $(<30 \%)$ and a high content of supplementary cementitious materials (such as Fly ash). To obtain useful early mechanical strengths $(>15 \mathrm{MPa}$ a 2 days) different alkaline activators were used (liquid and solid). The reaction products obtained were also characterised by XRD, SEM/EDX and ${ }^{27} \mathrm{Al}$ and ${ }^{29} \mathrm{Si}$ NMRMAS. The results showed that the main reaction product was a mix of cementitious gels C-A-S-H and (N,C)A-S-H, and that their relative proportions were strongly influenced by the calcium content in the initial binder
\end{abstract}

\section{Introduction}

The reduction of the Portland cement content in construction binders via replacement with supplementary cementitious materials (SCMs) such as slag, natural pozzolans or fly ash is a successful practice that has been in place for many years [1]. The use of SCMs has, moreover, been acknowledged by legislation the world over as a way of generating different types of cement and consolidated by unanimous reports that the practice leads to significant improvements in cementitious systems while contributing to sustainability.

The inclusion of fly ash in binders as a partial replacement for Portland cement, in addition to effectively reducing cement consumption, provides a solution for recycling this industrial by-product. Most standards limit the replacement ratio to under $55 \%$ [2], however, primarily because at higher percentages the early age mechanical strength of the cement declines substantially (when used alone, fly ash exhibits no hydraulic behaviour). One proposal (and one of the principal aims of the present study) for raising the ash content in OPC blends to $>70 \mathrm{wt} \%$ without compromising initial mechanical strength development and without having work at higher than ambient temperature is to alkali activate the blend. These alkaliactivated binders are known as hybrid cements [3].

The present study focused on alkaline activation as an excellent and effective procedure for reducing the clinker content in cements with good mechanical performance.

\section{EXPERIMENTAL}

This is an Open Access article distributed under the terms of the Creative Commons Attribution License 2.0, which permits unrestricted use, distribution, and reproduction in any medium, provided the original work is properly cited.
The present study used a clinker and two type F (FA1 and FA2) fly ashes. These materials were used to prepare Binder B1 (30\% clinker/70\% FA1) and B2 (20\% clinker $/ 80 \% \mathrm{FA} 2)$. B1 was hydrated with water (W, reference system) or an alkaline solution (N8, 8-M $\mathrm{NaOH}$ solution: $d=1200 \mathrm{~g} / \mathrm{L} ; \mathrm{pH}=13.3$; or $\mathbf{S S}$, a sodium silicate solution: $\mathrm{SiO}_{2} / \mathrm{Na}_{2} \mathrm{O}$ ratio=1.5; d=1 $200 \mathrm{~g} / \mathrm{L}$; $\mathrm{pH}=13.3)$. $\mathrm{B} 2$ was hydrated with water in the presence or absence of a solid activator in these cases $(4 \mathrm{wt} \%$ of $\mathrm{SAC}$ or $-\mathrm{SAS})$. The liquid/binder ratios used in each case were 0.45 for $\mathrm{B} 1$ and 0.4 for $\mathrm{B} 2$. These pastes were moulded into $1 \times 1 \times 6-\mathrm{cm}$ prismatic specimens and cured for 24 hours in a curing chamber $\left(22^{\circ} \mathrm{C}\right.$ and $99 \%$ relative humidity), after which the specimens were removed from the moulds and stored in the chamber until they reached the test age ( 2 and 28 days). The specimens were tested to failure on an Ibertest (Autotest -200/10-SW) test frame to determine their bending and compressive strength.

The material was ground (to $<45 \mu \mathrm{m}$ ) and subsequently frozen with an acetone/ethanol mix to halt further hydration. This material was characterised by XRD on a BRUKER AXS D 8 ADVANCE diffractometer fitted with a $4-\mathrm{kW}$ high voltage generator and a $\mathrm{Cu}$-anode $\mathrm{X}$-ray tube whose standard operating settings were $40 \mathrm{kV}$ and $50 \mathrm{~mA}$. The NMR studies were conducted with a BRUKER AVANCE-400 facility.

\section{RESULTS}

The bending and compressive strength values for the specimens are given in Figure 1. According to these findings, blends with low cement or clinker contents can yield materials with good cementitious properties provided a suitable alkaline activator is used. In all the 
cases studied, solution N8 (commonly used to alkali activate fly ash) failed to deliver the mechanical strength values sought. This was attributed to an excess of alkalis in the system, which retarded portland cement clinker hydration [4]. In highly alkaline media, $\mathrm{C}_{3} \mathrm{~S}$ hydration is known to be delayed substantially due to the common ion effect (the increase in $\mathrm{OH}^{-}$ion concentration in the system), and to the fact that the C-S-H gel may decompose in these media [4].

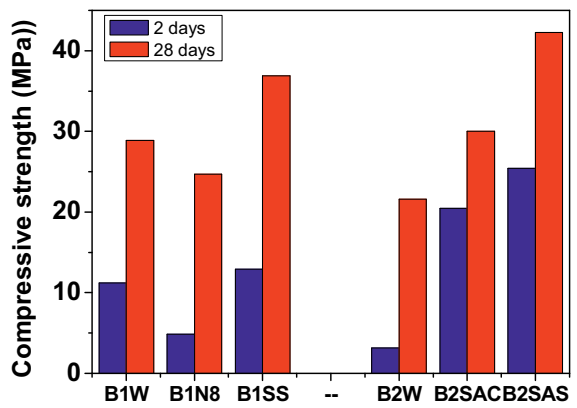

Figure 1. Compressive strength

However, when the SS solution (which contained a certain percentage of soluble sodium silicate), or solid activators (SAC and SAS) were used, mechanical strengths rose considerably in all cases. The use of Portland cement in the blends studied was nonetheless beneficial because in the presence of alkalis the heat released during cement hydration hastened fly ash dissolution. In these cases, the binders set and hardened at ambient temperature.

\section{$4 \quad$ Reaction products}

The XRD patterns for anhydrous blends B1 (30\% clinker/70 \% FA1) and B2 (20\% clinker/80\% FA2) as well as for the 28-day water- (reference system) and activated materials are reproduced in Figure 2. The diffraction lines for the clinker and ash constituents overlapped in the patterns for the two anhydrous materials. Both traces exhibited a halo attributed to the ash as well as lines associated with the crystalline phases of the clinker (alite, belite), and ash (quartz, mullite, hematite). A certain amount of calcite was likewise present in the starting blend, a result of partial weathering of the initial clinker.

The small amount of portlandite detected on the traces for both water-hydrated binders (B1-W and B2-W) confirmed that the clinker reacted. The portlandite signal was more visible in sample B1-W than in B2-W because the latter contained less clinker.

In the alkali-activated systems (B1N8, B1SS and B2SAC, B2SAS), hydration of silicate phases in the clinker was retarded since substantial amounts of alite were detected in the 28-day material. No portlandite was detected in these materials, although large amounts of calcium carbonate in the form of calcite were observed.

The absence of peaks associated with crystalline calcium hydroxide (portlandite) on the XRD spectrum did not, however, rule out the formation of the amorphous form of that compound.

Binder B2SAS contained ettringite in addition to calcite. The formation of ettringite would partially explain the higher mechanical behaviour of B2SAS. Ettringite is widely known to raise the volume of solids by $164 \%$, yielding a denser structure and significantly increasing the initial paste strength [5].
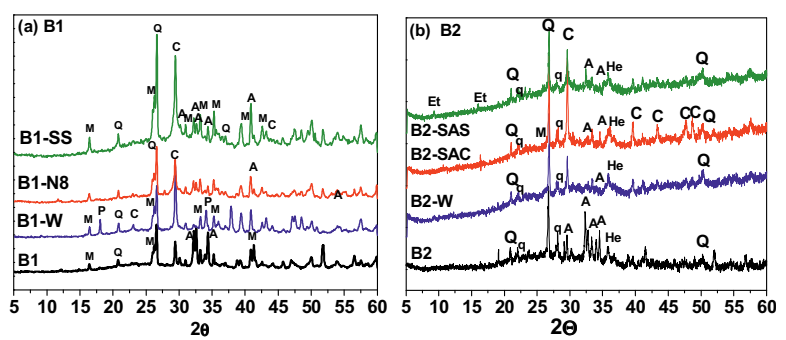

Figure 2. XRD patterns for (a) B1 and (b) B2 ( $Q=$ quartz; $q=$ quartz ; $\quad M=$ mullite; $\quad C=$ calcite; $\quad$ A=alite; $P=$ portlandite; $E t=$ ettringite, $\mathrm{He}=$ hematite)

Figure 3 shows a series of SEM micrographs of 28-day B1SS and B2SA. The cement matrix in both pastes shows some unreacted clinker and fly ash. The precipitation of a denser, more compact and more continuous product may partially explain the higher mechanical strength developed by these materials. The morphological analysis alone was insufficient to clearly distinguish whether a single gel or a mix of gels was forming, however. The microanalytical findings showed that this cementitious mass was formed entirely of $\mathrm{Na}$, $\mathrm{Ca}, \mathrm{Si}$, and $\mathrm{Al}$, although the percentage composition, especially of $\mathrm{Ca}$ and $\mathrm{Si}$, varied widely. Gels richer in $\mathrm{Ca}$ formed where a $\mathrm{C}_{3} \mathrm{~S}$ or $\mathrm{C}_{2} \mathrm{~S}$ particle was once located, whereas the $\mathrm{Si}$ and $\mathrm{Al}$ contents were higher in places formerly occupied by fly ash particles.

In other words, at least two types of gels can be distinguished: a C-A-S-H gel and a (N,C)-A-S-H gel. Na formed part of the composition of both gels, balancing the charge created when an $\mathrm{Al}$ tetrahedron replaced a $\mathrm{Si}$ tetrahedron.
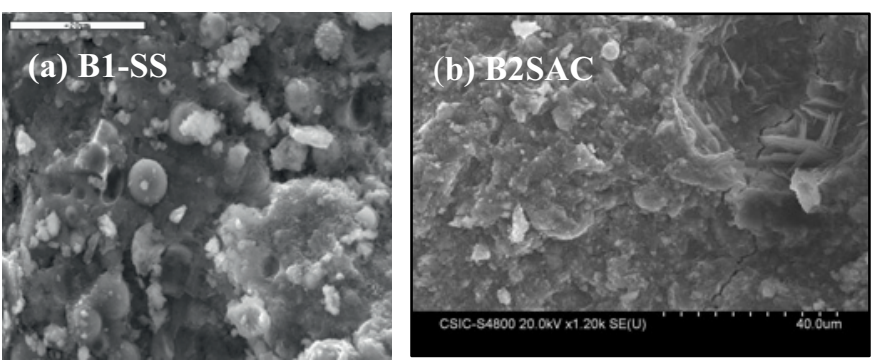

Figure 3. SEM micrographs of 28-day (a) B1SS and (b) B2SAC

Figure 4 shows the ${ }^{29} \mathrm{Si}$ MAS NMR spectra for the 28 -day systems. The ${ }^{29} \mathrm{Si}$ MAS NMR spectrum for the clinker contained a narrow, symmetrical signal with a bandwidth of around $15 \mathrm{ppm}$. This signal had a peak 
centred at $-71.38 \mathrm{ppm}$ and a shoulder at $-73.99 \mathrm{ppm}$, which respectively reflected the $\mathrm{Q}^{0}$ monomers or $\mathrm{Si}$ tetrahedra present in $\mathrm{C}_{3} \mathrm{~S}_{\mathrm{ss}}$ (alite) and $\mathrm{C}_{2} \mathrm{~S}_{\mathrm{ss}}$ (belite), the two main constituents of Portland cement [6]. The fly ash spectrum exhibited a wide signal centred at around $-108 \mathrm{ppm}$. This signal was characterised by a series of shoulders associated with the various forms in which the silicate appeared in the fly ash (mullite, vitreous phase, quartz, $\mathrm{Q}^{4}(\mathrm{nAl})$ and $\mathrm{Q}^{3}(\mathrm{nAl})$ units [7]).

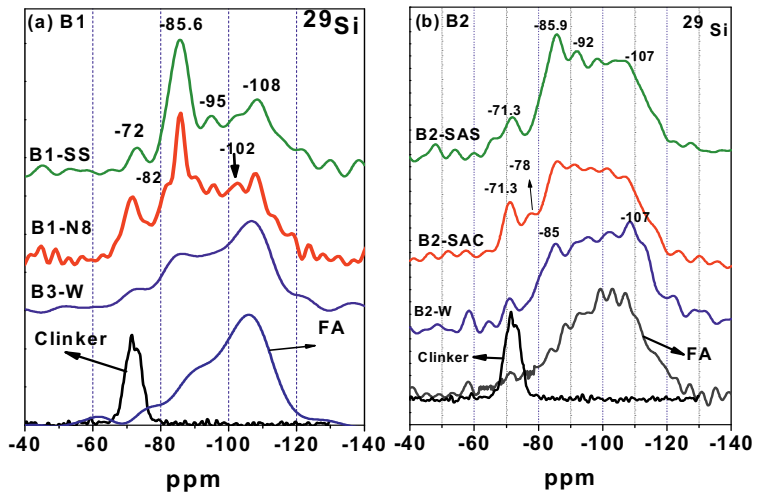

Figure 4. ${ }^{29} \mathrm{Si}$ MAS NMR spectra for (a) B1 and (b) B2

The signal at $-72 \mathrm{ppm}$ (attributed to the anhydrous silicates in the clinker) nearly disappeared in the spectra for the water-hydrated materials (B1-W and B2-W). The component associated with the presence of unreacted fly ash generated an intense signal (see peak at $-108 \mathrm{ppm}$ ) on the spectrum for the binder hydrated in the absence of a solid alkaline activator (binder $\mathrm{BH}$ ), an indication that under these conditions the ash was scantly reactive. The large amount of unreacted ash remaining in these materials would explain their lower mechanical strength. A new signal was observed in both B1-W and B2-W spectra at around $-85 /-86 \mathrm{ppm}$, which may have been associated with the presence of the $\mathrm{Q}^{2}$ units in C-S-H gel [6].

When alkaline activators were used a peak appeared at $-73 /-74 \mathrm{ppm}$, confirming the lower degree of clinker reaction in these highly alkaline media. The component initially associated with the unreacted fly ash was altered considerably in both systems.

A series of new signals was detected on these spectra, at $-86 /-87$, along with others at lower ppm (between -90 to $-100 \mathrm{pmm}$ ). These spectra cannot be readily interpreted because the signals emitted by the different gels overlapped among themselves and with the unreacted prime materials. In general these signals can be attributed to the presence of more polimerizated units, type $\mathrm{Q}^{3}(\mathrm{nAl})$ or $\mathrm{Q}^{4}(\mathrm{nAl})[3,8]$ that give rise to $\mathrm{C}-\mathrm{A}-\mathrm{S}-\mathrm{H}$ and $(\mathrm{N}, \mathrm{C})-\mathrm{A}-\mathrm{S}-\mathrm{H}$ gels.

In short, these observations suggest the formation of two types of gels [9,10].: i) a C-S-H gel taking aluminium into its structure as a result of its reaction with the clinker; ii) a N-A-S-H gel taking $\mathrm{Ca}$ into its structure as a result of the alkaline activation of the ash. Judging from the behaviour of synthetic gels, with time these gels would be expected to evolve into a new more thermodynamically stable gel [11]. These results further confirm that the activators used in this study enhanced the formation of a cementitious (C,N)-A-S-H gel.

Regarding the use of solid or liquid activators, their effect is strongly related to the initial alkalinity of the system. If the early alkalinity is extremely high (e.g. B1N8) the reactivity of the calcium silicate phases in the clinker component can be compromised, thereby negatively affecting early mechanical strengths. When the initial alkalinity is moderate (e.g. B1SS) or is only generated after the clinker has begun to react (e.g. B2SAC and B2SAS), the heat generated by the clinker reactions in such systems can accelerate the reaction of the ash and consequently result in a notable improvement in early mechanical strengths.

\section{4- Conclusions}

The present findings showed that a (hybrid cement) binder can be manufactured with a very low (30-20\%) clinker content and high (70-80\%) percentages of fly ash when activated with alkaline activators.

The presence of soluble silica in the activator played a decisive role in the development of mechanical strength. The addition of silica yielded denser matrices and a gel or gels richer in $\mathrm{Si}$. That produced hybrid cements with 28-day compressive strength values upward of $32 \mathrm{MPa}$ despite the low clinker contents.

In the absence of alkalis, these materials failed to develop initially suitable mechanical strength. By contrast, the presence of type and concentration of alkali activator and the heat released in initial cement hydration expedited the fly ash reaction substantially.

\section{Acknowledgements}

This research project was funded under Spanish Ministry of Science and Innovation project BIA201017530 .

\section{References}

[1] Naik T.R., Kraus R.N. and Siddique R., ACI Materials Journal, Vol.100, No 3, (2003), 208-215.

[2] EN-197-1:2011:

[3] Shi C., Fernández Jiménez A., Palomo A., Cement and Concrete Research 41, (2011), 750-763.

[4] Martinez-Ramirez S., and Palomo A. Advanced Cement Research 13 (3), (2001), 123-129.

[5] Shi. C. and Day R.L. Cement and Concrete research 30, 2000, 607-613.

[6] Cong X., Kirkpartrick R. J., Adv. Cem. Based Mater. 3, (1996), 144-156.

[7] Fernández-Jiménez A., Palomo A., Sobrados I., and Sanz J, Microporous and Mesoporous Materials, 91, (2006), 111119.

[8] Palomo A., Fernández-Jiménez A, Kovalchuk G, Ordoñez L.M, Naranjo M.C.. Journal Material Science 42, (2007), 2958-2966.

[9] Garcia-Lodeiro I, Fernandez-Jimenez A, Palomo A. (2013), Cement and Concrete Research (in press)

[10] Garcia-Lodeiro I, Fernandez-Jimenez A, Palomo A Cement and Concrete Composite 39, (2013)82-92

[11] I. Garcia-Lodeiro, A. Palomo, A. Fernández-Jiménez, D.E Cement and Concrete Research. 41, (2011), 923-931. 